\title{
DEMOCRACIA E POLÍTICA: LIMITES E ALCANCE DO SUFRÁGIO UNIVERSAL
}

\section{DEMOCRACY AND POLITICS: LIMITS AND REACH OF UNIVERSAL SUFFRAGE}

\author{
Eder Aparecido de Carvalho ${ }^{1}$, Alexandre da Silva de Paula² e Sérgio Kodato ${ }^{3}$ \\ 1 Instituto Federal Catarinense, Campus Brusque, Brasil, e-mail: carvalhoeder@hotmail.com, ORCID: \\ https://orcid.org/0000-0002-7472-2263 \\ 2 Centro Universitário de Votuporanga, Brasil, e-mail: aledpaula@outlook.com, ORCID: \\ https://orcid.org/0000-0002-6229-1478 \\ 3 Universidade de São Paulo, Faculdade de Filosofia, Ciências e Letras de Ribeirão Preto, Brasil, e- \\ mail: skodato@ffclrp.usp.br, ORCID: https://orcid.org/0000-0002-6427-1884
}

\begin{abstract}
ART I C LE INFO
Article history:

Received 2020-07-29

Accepted 2020-12-12

Available online 2020-12-12

Palavras-chave: Democracia. Política. Sufrágio Universal. Poliarquia. Emancipação.

Keywords: Democracy. Politics. Universal Suffrage. Polyarchy. Emancipation.

RESUMO. O problema que se coloca, neste ensaio teórico, é o da política, daquele poder que investe sobre a consciência, o corpo e a existência dos indivíduos, através de estratégias de micropoder e novas formas de dominação, como o sufrágio universal. Tendo em vista a democracia concorrencial, buscou-se analisar o distanciamento entre o cenário político ideal e o real e problematizar o papel do sufrágio, no sentido de assegurar a igualdade pretendida, em termos dos direitos constituídos. As eleições podem se constituir como um caminho para contestação do regime vigente e fator de transformação social? A pesquisa teve como objetivo analisar como o pleito eleitoral pode facilitar a escolha de um governo que atue em prol da maioria da população, pois isso é um fator preponderante para proteger o povo de um governo tirano. Enquanto método, amparou-se numa revisão teórica, para fundamentar a argumentação da proposta. Conclui-se, portanto, que a participação cidadã através do sufrágio universal é uma das garantias para a existência de uma democracia "plena" (poliarquia), dentro de um cenário público em que é decisiva a ação dos movimentos coletivos, em busca da emancipação e da politização das camadas desfavorecidas.
\end{abstract}

ABSTRACT. In this theoretical essay, it is in focus the politics' problem, of that power which invests on the awareness, the body and the existence of individuals, through micro power strategies and new domain ways, as the universal suffrage. Considering the competitive democracy, this study sought the analysis of the distance between the ideal and real political scenario and problematize the suffrage's role, in order to assure the intended equality, in the terms of the constituted rights. Can elections constitute themselves as a way to contest the current system and social transformation factor? The objective of this research was to analyze how elections can facilitate the choice of a governor that acts in favor of the minorities, because of that it is a preponderant factor to protect the population from a tyrant govern. As a method, it was supported by a theoretical review, to support the proposal's arguments. It could be concluded that, this way, the citizens' participation through universal suffrage is one of the warranties for the existence of a "plain" democracy ("polyarchy"), into a public scenario in which the action of the collective movements is decisive searching for the emancipation and politicization of the disadvantaged groups. 


\section{Introdução}

Este artigo, debatendo com as teorias clássicas da política, inspirado em uma concepção realista, traz à tona uma discussão contextualizada no horizonte atual da democracia liberal que, mesmo sob críticas constantes, permanece como um regime legítimo para a escolha dos representantes legais e autorização de governos. O conceito de soberania indica que, em diferentes perspectivas, se acentua a autonomia dos indivíduos, no exercício da cidadania pelo voto, fatos que não podem ser desprezados pelos grupos que ambicionam conquistar o poder. $O$ estudo, de revisão teórica, procura evidenciar alguns motivos que dificultam a participação dos cidadãos, nos processos decisivos da política eleitoral, o que impossibilita a efetividade do direito constitucional que trata da liberdade de escolha dos representantes que ocupam o poder público.

Os argumentos, que serão evidenciados ao longo do texto, envolvem a identidade do cidadão que se mostra na esfera pública com discernimento limitado, em uma sociedade complexa, além de distintas perspectivas sociológicas sobre a democracia, soberania e o exercício do poder. O estudo está contextualizado com as propostas originais, de autores clássicos das ciências políticas, que propuseram fundamentos para o funcionamento das democracias liberais no mundo globalizado. Num momento histórico em que a participação política apresenta sinais de atenuação no senso comum, indicando a desilusão do eleitor com a afetividade das propostas apresentadas nas campanha, nota-se a relevância de trazer à tona o quanto é fundamental, para manutenção de conquistas de diretos (civis e políticos) a compreensão das bases que articulam os sistemas democráticos liberais. Busca-se, além disso, indicar como o cidadão pode interferir, para além do voto, nos rumos da vida social.

\section{Método}

Trata-se de um estudo eminentemente de revisão teórica, pautado num enfoque qualitativo e compreensivo. A pesquisa adota a orientação de Minayo (2000), que considera a combinação e o cruzamento de múltiplos pontos de vista, a partir da sociologia clássica, na argumentação proposta no tema em questão: a democracia, o pleito eleitoral e a soberania popular. Esta modalidade de estudo "visa explicar os meandros das relações sociais consideradas essência e resultado da atividade humana, afetiva e racional, que pode ser apreendida através das explicações do senso comum" (MINAYO, 1992, p.11).

$\mathrm{Na}$ pesquisa de revisão teórica busca obter a compreensão dos fundamentos discursivos em autores com grande impacto e tradição acadêmica na área das ciências 
políticas. Assim, o problema formulado, tal como proposto, busca a compreensão de fenômenos políticos complexos, em sua historicidade, dinamicidade e interfaces com a identidade globalizada.

Cabe salientar que a interpretação do material teórico e bibliográfico, nessa perspectiva "[...] não é um processo de redução da riqueza e diversidade do objeto estudado a categorias preestabelecidas [...]" (Gonzales-Rey, 2005, p.32). Ou seja, a teoria está a serviço do pesquisador ao longo do processo interpretativo, não como fundamentação a priori. A interpretação, como elemento estruturante do método qualitativo, constitui, portanto, a atividade básica do pesquisador, como sujeito crítico, que produz ideias no decorrer da investigação, num processo permanente de integração e continuidade do seu próprio pensamento (Jodelet, 2009).

\section{Democracia direta e democracia representativa}

Os espaços públicos tomados ativamente pelos cidadãos, a fim de participarem diretamente das decisões da comunidade, associam-se ao conceito de democracia grega, o poder pertence ao povo. Hoje, esse conceito se aproxima da noção de um governo exercido por representantes do povo, ou seja, ilustra a passagem da democracia direta para a democracia representativa. Essa mudança ocorreu entre o século XIX e o XX. A democracia passou a ser vista como um procedimento eleitoral, para escolha dos representantes legais.

A democracia grega aparece como modelo de participação popular ideal, mas não real. Segundo Miguel (2005), não seria possível ter o "governo do povo" (propriamente dito), visto que as sociedades contemporâneas são densas e complexas. Nesta direção, Bobbio (2000), tecendo uma crítica à ideia de que na democracia todos podem apontar decisões, questiona quantos cidadãos dominam ou têm condições de propor soluções às complexidades do cenário econômico e social. Esse autor está se referindo ao pouco conhecimento formal e técnico do cidadão para proposições contra a inflação, melhoria na educação, programas de geração de renda, dentre outros fatores decisivos na administração pública.

$E$, no que diz respeito à democracia direta, cabe ressaltar, ainda, que o cidadão apresenta limitações para compreender, em profundidade, o sistema legislativo, uma vez que ele tem pouco acesso ao conhecimento que trata das doutrinas jurídicas (BOBBIO, 2000). Contudo, cabe salientar que as diversas formas que o Estado assumiu na sociedade capitalista estiveram ligadas à concepção de soberania popular (poder do povo), a base da democracia moderna.

Indicando problemas desse sistema, Bobbio (2000, p. 47) alerta que "todos os Estados que se tornaram mais democráticos tornaram-se, ao mesmo tempo, mais burocráticos". A inevitabilidade da organização burocrática mostrou-se no mesmo passo em que foram se expandindo as funções do Estado. Weber (2000) acrescenta que a democracia é uma 
competição entre os grupos organizados (partidos com poder crescente de burocratização) e seus dirigentes, na disputa pelos votos dos eleitores. O pensador alemão cita Jean-Jacques Rousseau, afirmando que o povo é soberano momento da eleição, deixando de sê-lo logo em seguida.

Nessa concepção, após o pleito, nem o povo e nem os partidos teriam o direito de pedir satisfações ao eleito. Ou seja, na democracia liberal, a soberania não pertence à população, porém, ela não pode ser ignorada pelos líderes. Assim, caberia aos candidatos manterem uma imagem pública de aprovação, para não perderem a base popular. $O$ autor citado anteriormente defende, ainda, que os partidos políticos atuam como organizações voluntárias na busca constante pela hegemonia no poder e conclui que eles têm a função de angariar votos para os seus candidatos obterem êxito.

Seguindo a concepção weberiana, encontram-se os posicionamentos de Schumpeter (1961) e Dahl (1997), os quais afirmam que democracia é um método de escolha e autorização de governos. Nesta abordagem política, o povo também não teria a soberania, mas seria o meio para se chegar até ela. O cidadão poderia, através de sua consciência, concluir que o governo que conduz a nação com uma má gestão deve ir à forca com ele, por exemplo, nos processos legítimos de impedimento.

Schumpeter (1961) defende um conceito de soberania divergente da tradição clássica, ou seja, a concepção que postula a soberania do povo. Para este autor, na democracia não existe o governo pelo povo, mas sim, um governo aprovado pelo povo. A ideia de um governo do povo, no âmbito desta corrente da democracia representativa, "é esvaziada na medida em que aos cidadãos comuns cabe, sobretudo, formar o governo, mas não governar" (MIGUEL, 2005, p.7-8). O indivíduo produz um governo, ou melhor, um corpo intermediário que produz um governo.

O autor citado prossegue e argumenta que, embora a soberania não esteja centralizada na figura do cidadão, ele detém o poder de escolha, ou seja, a soberania das massas não é nula ou desprezível para os pilares da democracia. Essa é a grande diferença entre os regimes liberais democráticos e os regimes autoritários. O primeiro, em virtude de uma competição pelo voto em que os candidatos são controlados pelo povo, é um regime que se propõe, ao invés do autocrático que se impõe.

Diferente das propostas de Schumpeter e Dahl, tendo como referência a filosofia de Espinoza, Chauí (1980, p. 22) destaca um dos pilares dos regimes autoritários, a saber, a superstição. A autora pontua que a superstição "está na base de todo o Estado autoritário e despótico, onde os chefes se mantêm fortes alimentando o terror das massas, com medo dos castigos e com suas esperanças de recompensa". A crítica à superstição, ou ao conhecimento desprovido da racionalidade científica, é uma diretriz para a conduta ética na política e, por conseguinte, para a liberdade humana. 
"Quando o poder político, para assegurar-se, une-se com o poder religioso e usa a superstição como arma, tende a censurar a liberdade de pensamento e de expressão [...] a censura gera o descontentamento e este se expande para a massa" (CHAUÍ,1980, p. 23). Com relação ao conceito de democracia, a autora destaca que pode haver conflitos entre os interesses do Estado e os interesses do cidadão.

Se o conflito é tal que aniquila os cidadãos, estes naturalmente se revoltam. A revolução está inscrita no interior do próprio Estado quando este é contrário às necessidades da comunidade. Assim sendo, o Estado menos violento e menos conflituoso só pode ser o Estado democrático (CHAUÍ, 1980, p. 22).

Tocqueville (1987), por sua vez, define a democracia como o aumento constante das igualdades de condições entre os cidadãos - igualdade política, econômica e cultural. O autor citado, assim como Dahl (1997), compreende que a participação é o veículo principal para proteger a democracia de um governo tirano ou fascista. Tanto Tocqueville, como Dahl, defendem a aplicação de regras definidas pela maioria, as quais deveriam assegurar a liberdade de escolha pelas minorias.

$\mathrm{Na}$ vertente marxista, a democracia é definida como uma forma específica de dominação da burguesia para manter o sistema capitalista. Nesta abordagem, afirma-se que, dentro do mercado político, não existe igualdade de competição entre os candidatos. Haveria partidos com mais recursos econômicos que outros, exercendo uma pressão decisiva sobre a escolha representativa. Assim, para Marx (1998), ao invés de se ter um sistema político em favor do equilíbrio entre os pares, tem-se um sistema que favorece as desigualdades na competição partidária. É, neste âmbito, que se compreende como o mercado da política é oligopolizado por poucas empresas que atuam no marketing e financiam os custos elevados das campanhas eleitorais.

Dahl (1997) se opõe aos preceitos marxistas, negando que exista uma classe dominante. $\mathrm{O}$ autor compreende que existem muitos grupos minoritários que disputam, entre $\mathrm{si}$, interesses específicos nos jogos de poder e que devem ser considerados pelos governantes, no alinhamento de suas propostas. Nesse sentido, o autor enfatiza que a existência de vários grupos, disputando o poder, revelaria uma sociedade em um estágio político avançado. O poder seria efetuado por múltiplas forças, com origem em seguimentos sociais diversos, sendo fracionado em coligações e alianças partidárias de caráter pluralista.

Esse posicionamento é semelhante aos conceitos de Schumpeter (1961), o qual define os partidos políticos como grupos organizados que agem de forma sistêmica dentro da competição eleitoral, na busca pelo voto do eleitorado. Diferente da teoria clássica (tradicional), que idealizou o cidadão total, Schumpeter (1961) postula um cidadão sem ideologia definida, com pouco discernimento das questões sociais. O autor propõe um diagnóstico do cidadão moderno, discutindo a profunda incapacidade de julgamento ou esclarecimento. 
Dahl (1997), de maneira semelhante, salienta o desinteresse e a apatia do eleitorado quanto à agenda política. O autor destaca, no entanto, que pode haver mobilização, quando interesses específicos de grupos sociais são colocados em pauta. No contexto atual, percebese o quanto pautas de cunho moral e programas de correção dos costumes, com base no idealismo religioso, têm despertado o ativismo político no Brasil. Contudo, destaca-se que os motivos que dificultam a participação dos indivíduos na política aparecem de forma distinta, segundo as análises de Schumpeter e Bobbio.

O primeiro autor enfatiza a conduta popular motivada por mecanismos de pensamento compreendidos como irracionais, salientando a manipulação das massas, como se houvesse o predomínio de um comportamento infantilizado, incivilizado ou regredido, ao tomar decisões de cunho político. Nesse caso, o cidadão teria mais preocupação com decisões da vida privada, do que com temas de interesse público. O segundo autor indica que é o aumento da complexidade social, dentro de um sistema democrático, que constitui o elemento desestabilizador da participação.

Já, quanto à deficiência da democracia, para Bobbio (2000), esse fato não estaria nas promessas que o político deixou de cumprir, mas sim nas promessas que deixou de fazer. $O$ autor reconhece que há longos espaços para o aperfeiçoamento da democracia. No Estado, ainda há mecanismos autocráticos que persistem na prática cotidiana dos agentes públicos. O autor observa a existência, na democracia, de centros de poder (exército, burocracia e serviços secretos) que constituem a parte oculta da democracia. Trata-se de instrumentos que não estão sob um controle democrático, ou seja, "mesmo numa sociedade democrática, o poder autocrático está muito mais disseminado que o poder democrático" (BOBBIO, apud ANDERSON, 2002, p. 226).

Concluindo essa temática, Weber (2003) não apresenta preocupações com o nivelamento igualitário da sociedade ou a busca de um consenso político. O autor defende um projeto que permita a formação do Estado-nação como potência. Sobretudo, na concepção de Weber, certas esferas da política não são atingidas, por exemplo, aquelas que envolvem o segredo da profissão. Assim, certas áreas não são transparentes e nem públicas. Nesses casos, a burocracia faz uso do segredo de gabinete para elevar o seu poderio (WEBER apud BOBBIO, 2000b).

Enfim, nota-se, na herança realista da sociologia desenvolvida por Weber, um alerta para os elementos que esvaziam o Estado representativo. Em síntese, percebe-se que tanto para Weber quanto para Bobbio (ambos realistas), há um Estado visível que é regido pela transparência, tendo como contrapartida o Estado invisível, privado de transparência. Ou seja, existe um movimento ditatorial onde uma face da democracia representativa não é revelada.

Sobretudo, chama a atenção que, nesta relação entre soberania, Estado e democracia, é prudente o apontamento de Espinosa (1981, p. 332) a afirmar que "é certo que 
não há ninguém que não goste mais de governar do que ser governado; ninguém cede voluntariamente o comando de outrem [...]. Nesse aspecto, retomando a polêmica entre a democracia e as possibilidades de oposição ao espectro autocrático do Estado, que pode se manifestar com atos ditatoriais, Chauí (2003) indica que a estabilidade política, segundo o pensamento spinoziano, decorre da multiplicação de conselhos e assembleias com a maior participação popular. "Se o povo, excluído dos negócios públicos, que são tratados a sua revelia, for capaz de moderação e de juízo correto, então merece governar, em lugar de ser governado" (CHAUÍ, 2003, p. 295).

\section{Participação, cidadania e pluralismo}

A participação, tão citada, ainda é um dos problemas para a existência de uma democracia plena, na sociedade contemporânea. Dahl (1997), entretanto, argumenta que a não participação é, ainda, pior do que a participação, mesmo frágil, tendo em vista que a referida ação coletiva pode mudar os destinos de uma nação. Putnam (2006), por exemplo, reforça que a qualidade da participação do cidadão influencia as instituições existentes. Assim, cada povo teria o governo que traduz seus ideais.

Havendo limites à competição entre os candidatos no pleito eleitoral, ou sendo negado o direito do voto, o regime em questão não é democrático. Os regimes são diferenciados levando em consideração a proporção de pessoas aptas para participar de forma ativa e consciente. Diante disto, Dahl (1997) chama atenção para a necessidade de garantir aos cidadãos, somado à competição, as seguintes oportunidades: liberdade de expressão, direito ao voto, processo eleitoral livre e idôneo e, principalmente, instituições para a garantia desses direitos.

Oportuno destacar que, até o último quarto do século $X X$, a literatura trazia a democracia ou autoritarismo como regimes derivados da existência (ou não) da modernização - urbanização. Neste sentido, Lipset (1967) argumenta que um país tende a ser mais ou menos democrático, segundo os critérios da modernização. Há uma relação causal entre esses dois fatores: mais chances de democracia nos países desenvolvidos e menos em países em desenvolvimento. De um lado, chama a atenção para o fato de a democracia estar associada ao processo de modernização, e de outro, o nível da própria democracia estar diretamente relacionado com o nível de desenvolvimento socioeconômico das nações. Consequentemente, os regimes autoritários tendem a ocorrer em países em desenvolvimento.

Do ponto de vista de Lipset (divergindo de Dahl e Putnam), a baixa participação popular em sistemas de voto facultativo (maior a taxa de abstenção eleitoral) revelaria a própria solidez da democracia. Na mesma linha, Huntington (1975) ilustra que o excesso de participação amplia as desavenças que o Estado é capaz de processar. Dahl (1997), por sua vez, aponta uma direção oposta aos argumentos apresentados por Lipset. Esse autor busca 
compreender as variáveis políticas que interferem no processo democrático. Desse modo, salienta desde a autonomia até as variáveis que vão além da modernização, tais como: a contestação e a participação. Assim, indaga: quando há espaço para as manifestações de oposição (contestação), qual é o grau de inclusão (participação) do cidadão?

Todavia, num país em que há deliberados mecanismos de censura, a contestação surge constrangida em suas demandas por reinvindicação política. $\mathrm{Na}$ ausência do contraditório, do direito de exercer a oposição, ampliam-se as lacunas da participação cidadã.

Um país com sufrágio universal e com um governo totalmente repressivo certamente proporcionaria menos oportunidades a oposições do que um país com sufrágio limitado, mas com um governo fortemente tolerante. Consequentemente, quando os países são classificados exclusivamente de acordo com sua capacidade de inclusão sem levar em conta as circunstâncias ambientes, os resultados são anômalos (DAHL, 1997, p. 28-29).

Como apontado anteriormente, Dahl (1997) salienta a importância das instituições para o processo de democratização, afirmando que há vetores que vão além da modernização, como a inclusão popular e a competição honesta por vagas, no sentido de aproximar a realidade da poliarquia (democracia possível). Quanto mais plural (grupos organizados, partidos etc.), maior a proximidade de uma sociedade democrática plena. $\mathrm{O}$ pluralismo evitaria que um grupo social específico tivesse domínio do poder. A probabilidade de uma democracia funcionar em um país decorre, portanto, do grau de pluralismo da sociedade.

Cabe ressaltar que a maioria dos países, hoje desenvolvidos e que se tornaram democráticos, era pluralista no século XIX, antes mesmo da modernização. Da mesma forma, não haveria incompatibilidade entre democracia e subdesenvolvimento, uma vez que o governo democrático nos países em desenvolvimento dependeria, também, do grau de pluralismo existente no meio social. O pluralismo societal permite superar o determinismo presente na teoria da modernização (DAHL, 1997).

Quanto ao pensamento de Bourdieu (1981), nota-se que o modo como o regime funciona tem relação direta com a redução da participação popular (o que favorece a imposição de convicções dos dominadores como sendo o ponto de vista universal). Consequentemente, o autor vislumbra um conflito com o ideal democrático - distanciamento entre o ideal e o real. É possível afirmar que o Estado se apropria do pensamento dos cidadãos, e a autonomia dos homens em relação às estruturas é delicada.

Bourdieu (2014) alerta contra o perigo da dominação do Estado. Neste sentido, o autor enfatiza que a tomada de consciência pelo povo (mudança de mentalidade) possibilita a construção de estratégias capazes de contrariar as forças instituídas. No entanto, a mudança de mentalidade, tão fundamental, se apresenta como tarefa complicada a realizar, devido a 
mecanismos de controle e manipulação das massas, ou seja, a forma com que a maioria é governada pela minoria.

Em síntese, percebe-se que a democracia é um sistema dinâmico, um processo em constante transformação. Essa metamorfose, mesmo revelando dificuldades para efetuação do poder popular, não inviabiliza afirmar as potencialidades para a cidadania plena e justa. É notório que entre o ideal e o real há uma longa distância. Um dos desafios passa pela tentativa de reduzir esta distância: real versus ideal. Neste aspecto, cabe salientar o contraponto da perspectiva de Espinosa, tal como esclarece Chauí (2003, p. 170):

O que se distribui não é a soberania, pois esta permanece com a multitudo (massa), e sim o direito de participação no poder. O que distingue os regimes políticos não é, portanto, a origem do poder (a origem é sempre a mesma, a massa com corpo único e causa única), nem o número de governantes (pois o governante não é idêntico à soberania), mas a definição do direito de exercer o poder.

No Brasil, as recentes desilusões (desapontamentos) e ressentimentos, com governos passados, não devem se sobrepor ao ideal democrático: possibilidade de competição e participação ampla, envolvendo todos os cidadãos, para além do momento do voto. Isso deve ser resgatado, especialmente, porque se multiplicam o desinteresse, o cansaço e a apatia pela maioria das pessoas, no que tange aos assuntos ligados à política. Há os que não participam do processo político por desconhecer o seu papel, entretanto, existem os que são indiferentes e cônscios, ou seja, os apolíticos. Neste momento histórico, a coalisão de forças na sociedade civil, em prol da democracia participativa, é um imperativo, um norte para um Estado em condições precárias de funcionamento e limitadas projeções para o futuro.

\section{Identidade e cultura pós-moderna}

A identidade, como afirma Hall (1997), se constitui no interior de práticas de significação, circunscritas em uma dimensão histórica e cultural. No processo de constituição de identidade, a diferença na relação com outro é o que possibilita, ao indivíduo, afirmar sua posição de sujeito. A relação com a diferença do outro, na constituição da identidade, é assinalada por Guareschi et al. (2003, p. 131), onde "o processo de construção de identidades sempre se refere a um outro, ou seja, eu sou algo a partir daquilo que eu não sou, ou eu não sou o que o outro é". É na diferença com o outro que podemos afirmar nossa posição identitária. Em contrapartida, as próprias contradições que decorrem das diferenças promovem as mudanças em nossas identidades.

Oportuno destacar que (no âmbito da teoria social contemporânea) a cultura aponta para o campo das diferenças. Segundo Lévi-Strauss (1976), a diversidade é essencial para a existência da humanidade. A própria homogeneização produz (ou reproduz) de novo a 
diversidade. A diversidade sempre retorna e, mais uma vez, é homogeneizada. Na concepção de Appadurai (2004), a identidade é conceituada de uma forma dinâmica, não é fixa e estática. Não é estanque, mas sim fluida. Identidades são recriadas. É a partir deste sujeito pósmoderno, que não apresenta identidade fixa, que Stuart Hall também promove a discussão no que tange à crise de identidade.

Ao passo que a sociedade sofre transformações econômicas e políticas, o indivíduo sofre com mudanças na sua identidade - descentralização ocasionada pela globalização e um hibridismo das culturas (fusão entre diferentes tradições culturais), originado pela diáspora. Inclusive, segundo Stuart Hall, não seria possível afirmar que temos uma "identidade", uma vez que os indivíduos na sociedade são compostos por uma identificação (processos identitários) passível de modificação e transformação.

É possível afirmar que as sociedades pós-modernas transpõem fronteiras, territórios, campos fechados etc. Ou seja, os efeitos da globalização foram desterritorializando as identidades e demolindo os seus marcos originais (LASH, 1990). Segundo Hall (1997), nossas identidades poderiam ser conceituadas a partir das sedimentações, através do tempo das diferentes posições que adotamos e procuramos viver. Enquanto somos todos translocais, para Fortuna (1999), há uma descaracterização da identidade e da subjetividade.

Canclini (2000) observou que, até o século XIX, as conexões culturais se davam entre grupos próximos, o que possibilitava as trocas simbólicas e o reconhecimento de si e do outro. Nesse período, segundo Mancebo (2002), o investimento do poder disciplinar forneceu um discurso científico sobre as identidades, a partir do saber médico, jurídico, sociológico, antropológico e psicológico os quais funcionaram como agentes que inspecionavam os problemas oriundos da industrialização e da urbanização. Esses saberes atuavam como agentes de controle social, das formas de subjetivação mobilizadas na modernidade, classificando os indivíduos em conceitos identitários e padrões de conduta.

As identidades são compreendidas dentro de uma formação cultural em movimento, são intercambiáveis e inscritas na dimensão simbólica das práticas cotidianas que são determinadas por um contexto sócio-histórico. O sujeito contemporâneo carece de identificação com localidades e regionalidades, evidenciando o conceito de migração (diáspora). A cultura local perde força, diante da cultura global, a qual assume o protagonismo. As tecnologias de comunicação de massa acabam por priorizar o global, em detrimento do local (BERNARDES; HOENICSH, 2003). Os autores citados afirmam que o conceito de identidade, cunhado na modernidade, remete a uma essência e a uma forma fixa de um sujeito natural, absoluto, totalizado e uno.

Essa posição foi inspirada na filosofia socrática que outorgou, para o pensamento ocidental, o princípio de identidade. "Tal princípio é da ordem da semelhança eterna do ser; só se constitui o ser a partir da imobilidade e do eternamente igual, do idêntico a si”. 
(BERNARDES; HOENICSH, 2003, p. 115). Os autores citados argumentam ainda que, no século $\mathrm{XX}$, as tecnologias de comunicação possibilitaram trocas culturais, de tal maneira que não se sabe mais a origem delas. O que se observa, no contexto atual, é uma cultura mundial - globalizada.

Com efeito, as identidades pós-modernas são influenciadas pelas informações globalizadas, desenhando-se uma nova configuração de cidadão e participação democrática. As identidades e a cultura têm sido moldadas pelo influxo da globalização e das modificações que se processam no espaço geográfico, físico ou virtual. Anteriormente, no início do período moderno, o controle social era produzido pelos dispositivos disciplinares, bem como pela normatização tecnocientífica que ordenava o lugar do indivíduo, na sociedade industrial. As escolhas dos indivíduos eram movidas pela exigência de se alcançar essa suposta identidade normalizada, evitando sucumbir à culpa (ROLNIK, 1999).

No mundo contemporâneo, observa-se um cidadão cada vez menos participativo e mais preocupado com o deleite das cobiças pessoais - prioridade do privado em detrimento do público (CANCLINI, 2005). Nota-se o quanto as identidades nas sociedades pós-modernas envolvem contradições e diferenças culturais, as quais contribuem para a sedimentação e a descontinuidade, promovendo, assim, novas mutações no eu. Nesse movimento, as identidades podem ser concebidas como resultado de um processo de identificação que permite aos indivíduos se posicionar, no interior das culturas locais ou plurais.

O processo de afirmação da identidade e a enunciação das diferenças pressupõem o desejo de os grupos imporem sentidos, crenças, valores e regras. O poder está presente tecendo as relações de formação das identidades. Um poder que não reprime ou oprime, mas um poder que produz diferenças e atos de significação (BERNARDES; HOENISCH 2003). Cabe salientar que Appadurai (2004) defende a viabilidade de uma democracia, enfatizando a influência dos meios eletrônicos de comunicação, os quais podem propiciar as novas singularidades. Ou seja, o autor afirma que meios de comunicação interferem na produção de subjetividades, assim, não podem ser reduzidos a meros fatores de alienação.

A comunicação em rede é apropriada para constituir comunidades globais, segundo uma concepção de cultura que toma a complexidade do mundo como fundamento para compreender as relações interculturais. $\mathrm{O}$ autor citado acrescenta que o objetivo de construir essas comunidades plurais seria a multiplicação da cultura, onde todas as memórias pudessem dialogar, para além do uso maniqueísta, propagandista e ideológico que falsifica intenções, metas e projeções dos candidatos.

\section{Discussão}

Pode-se entender a eleição como um processo pelo qual um grupo de indivíduos designa um ou mais de um de seus integrantes para ocupar um cargo público ou privado, por 
meio de um sistema de votação. Na democracia representativa, esse processo implica na escolha de determinados indivíduos para exercerem o poder soberano, concedido pelo povo através do voto, devendo estes, assim, exercerem o papel de representantes da nação. $A$ eleição pode se processar com o voto de toda a comunidade (sufrágio universal) ou de apenas uma parcela da comunidade, isto é, grupos restritos de pessoas que preencham certos requisitos econômicos, sociais e culturais (sufrágio restrito).

Sem dúvida, uma democracia forte deve conter em seu repertório procedimental institutos de democracia direta, tais como o do plebiscito. Além disso, uma sociedade é mais plenamente democrática quanto mais possui fóruns patrocinados pelo Estado e fomentados pela sociedade civil para discussões sobre políticas, e pelos menos alguns deles devem influenciar procedimentalmente as decisões governamentais. A posição anti-representação, no entanto, recusa-se a encarar as realidades complexas do processo democrático e erroneamente opõe a representação à participação (YOUNG, 2006, p. 144).

No aspecto político, é notório que a conquista do voto não garantiu a igualdade pretendida, visto que as decisões são mediadas e influenciadas pelos grupos dominantes. De qualquer forma, o sufrágio possibilita uma capacidade de contestação que não pode ser desprezada. Por outro lado, chama atenção a reflexão de Gasparado (2018, p. 73) sobre a democracia participativa, processo que acentua a própria "pluralidade de desenhos institucionais, pois eleger representantes não é a única forma de participar das decisões políticas". O autor argumenta que, com relação a arquitetura institucional, essa forma de exercício da cidadania pode ser de baixa intensidade (restrita ao momento do pleito) ou alta intensidade (abrangendo desde o programa do candidato, até a execução das propostas).

Contudo, dentre os muitos desafios, é necessário preencher os longos espaços que a democracia promove para a educação e a cidadania. É um fato que os meios eletrônicos e a globalização da cultura promovem ressignificações identitárias. É possível afirmar que toda identidade (ou melhor, identificação) é móvel e pode ser redirecionada. A comunicação em rede eletrônica (celular, computador, Internet etc.) e o fenômeno da globalização extrapolam os espaços geográficos e temporais e comprometem a definição de identidades fixas. Esses dispositivos de comunicação têm sido decisivos nos últimos pleitos e disputas políticas. De fato, destaca-se que o marketing político tem investido, em larga escala, no ramo da comunicação por mídias sociais, influenciando de forma crucial as atitudes do eleitor.

A interação via comunicação transcultural, somada à circulação dos indivíduos (migrantes, refugiados, turistas, profissionais etc.), têm colaborado junto à construção de formas culturais híbridas e plurais. O desafio - neste âmbito - passa pelo dever de o Estado tirar proveito dos benefícios trazidos pela globalização sem, é claro, não se esquecer das 
necessidades e das peculiaridades locais. Com efeito, Segundo Gerschman (1997) no contexto da globalização capitalista, observa-se o elogio aos sistemas democráticos, porém, diante de modelo hegemônico de competição entre os partidos, predomina a exclusão social. "Isso não acontece exclusivamente na parte arcaica do mundo global; existe também nos países desenvolvidos, ainda que de maneira suavizada [...]" GERSCHMAN, 1997, p. 54).

No contexto histórico-cultural da pós-verdade, onde crenças individuais se sobrepõem às evidências científicas, a participação dos cidadãos no cenário político e eleitoral é prejudicada devido à propagação de calúnias e acusações sem fundamento. Muitas vezes, os julgamentos e critérios de escolha dos representantes não são condizentes com fatos. Isso fragiliza a participação ética, articulada com problemas estruturais do país, os quais deveriam constar na agenda e nos planos de governo. Como elemento que vem configurando novas forças, neste cenário, emerge uma tendência internacional de direita, a qual ampliou, de maneira efetiva, seus territórios e domínios, com grande impacto na geopolítica mundial.

Sorj (2007) destaca que, uma das consequências, é uma tendência a propagação discursos negacionistas ou revisionistas da história, os quais atacam um legado de conhecimentos sistemáticos que marcaram os rumos políticos e econômicos da modernidade, o Holocausto tem sido um desses temas. A autora citada argumenta que o "negacionismo" que teve início recente na Europa "foi assimilado pelo radicalismo islâmico como estratégia política na luta contra a existência do Estado de Israel. Ao mesmo tempo, aparece no espaço público, a construção simbólica de analogias entre Israel e os nazistas" (p. 112).

Essas situações reforçam que é indispensável considerar que o processo democrático do país exige a ampliação de uma competição transparente e digna entre os atores públicos, para além da troca de acusações de cunho moral e ideológico, enquanto estratégia meramente caluniosa e desprovida de proposições, perante os problemas sociais e econômicos. Além disso, são imperativas a crítica e a denúncia dos crimes eleitorais por parte de entidades competentes e distintos setores da sociedade civil, contribuindo para o esclarecimento do cidadão.

Essa pauta envolve um dos maiores problemas para a existência de uma democracia plena. Desse modo, nota-se a necessidade de ações coletivas em prol de transformações radicais na participação do cidadão, no sentido de despertar a consciência política, a capacidade de questionar e problematizar informações distorcidas, propagandas falsas, abrindo caminho para buscar, cada vez mais, evidências e coerência com a realidade na argumentação e nas metas dos candidatos. É necessário, portanto, fortalecer a compreensão popular dos interesses ocultos que interferem no processo de consolidação da democracia brasileira, com destaque para esse momento de crise política que se instaura na América Latina. A situação é de ameaça aos direitos sociais conquistados pelas minorias, nas últimas décadas. Quanto mais plural, diverso e ético o cenário da disputa política, maior a proximidade de uma sociedade democrática plena. 


\section{Considerações finais}

É possível que os eleitores se preocupem prioritariamente com o seu bem-estar material, mas é preciso conscientizá-los de que eles possuem o instrumento do voto, com o qual podem punir os maus governantes, por decisões erradas, e podem decidir responsabilizar o governo por decisões em áreas, que não a econômica, que atentam contra o bem comum e a democracia. Se os eleitores usassem o voto com um sentido de futuro, buscariam escolher governos cada vez melhores e representativos, simplesmente porque executariam boas políticas públicas. Mas os políticos assim que são escolhidos, parece que se esquecem das suas promessas, do sistema de representação e perdem o medo da sanção eleitoral.

Nesse sentido, deveríamos acompanhar a relação entre desempenho executivo ou legislativo e sobrevivência política, mesmo que os eleitores estejam usando seus votos como moeda de troca, em torno de interesses pessoais. Ainda que o uso oportunista do voto reduza o poder de crítica sobre os governantes, o desempenho passado do governante deve ser considerado para informar aos eleitores sobre a probabilidade de que ele cometa atos contra o bem comum. Assim, existem boas razões para se esperar que os governos devem buscar representatividade, quer porque temam sanções eleitorais futuras, quer porque bons políticos buscam sempre melhorar sua avaliação perante seus eleitores. Devemos, ainda, observar que quando os governantes com mau desempenho são removidos de seus postos, isso leva a um fortalecimento da democracia representativa.

\section{REFERÊNCIAS}

ANDERSON, Perry. Afinidades Seletivas. Tradução de Paulo César Castanheira. São Paulo: Boitempo Editorial, 2002.

APPADURAI, Arjun. As Dimensões Culturais da Globalização. Tradução de Telma Costa. Lisboa: Teorema, 2004.

BERNARDES, Anita Guazzelli; HOENISCH, Júlio César. Subjetividade e identidades: possibilidades de interlocução da psicologia social com os estudos culturais. In Neuza Maria de Fátima Guareschi; Michel Euclides Bruschi (Orgs.). Psicologia Social nos estudos culturais: perspectivas e desafios para uma nova psicologia social. Petrópolis: Vozes, p. 95126, 2003.

BOBBIO, Norberto. O futuro da democracia. Tradução de Marco Aurélio Nogueira. São Paulo: Paz e Terra, 2000a.

A teoria Geral da Política: a filosofia política e as lições dos clássicos. Tradução de Daniela BeccacciaVersiani. Rio de Janeiro: Campus, 2000b. 
BOURDIEU, Pierre. Sobre o Estado. Tradução de Rosa. Freire d'Aguiar. São Paulo: Companhia das Letras, 2014.

BOURDIEU, Pierre. "La Représentation politique. Éléments pour une théorie du champ politique". Actes de la Recherche en Sciences Sociales, n. 36-37, p. 3-24, 1981.

CANCLINI, Néstor García. Culturas híbridas: estratégias para entrar e sair da modernidade. Tradução de Ana Regina Lessa e Heloísa Pezza Cintrão. São Paulo: Edusp, 2000.

Consumidores e Cidadãos: conflitos multiculturais da globalização. Tradução de Maurício Santana Dias. 5‥ Ed. Rio de Janeiro: Editora UFRJ, 2005.

CHAUÍ, Marilena. Política em Espinosa. São Paulo: Companhia das Letras, 2003.

COHN, Gabriel. Introdução. In: WEBER, Max. Parlamento e Governo na Alemanha Reordenada: crítica política do funcionalismo e da natureza dos partidos. Tradução de Karin Bakker de Araújo. Petrópolis: Editora Vozes, 1993.

DAHL, Robert. A. Poliarquia: participação e oposição. Tradução de Celso Mauro Paciornik. São Paulo: EDUSP, 1997.

Tratado Político. Tradução e notas de M. S. Chauí. 2ª ed. São Paulo: Abril Cultural, 1981. Coleção Os Pensadores

FORTUNA, Carlos. Identidades, Percursos, Paisagens Culturais. Oeiras: Celta, 1999.

GASPARDO, Murilo. Democracia participativa e experimentalismo democrático em tempos sombrios. Estudos Avançados, São Paulo, v. 32, n. 92, p. 65-88, 2018. Disponível em $<$ http://www.scielo.br/scielo.php?script=sci_arttext\&pid=S0103-

$40142018000100065 \&$ Ing=en\&nrm=iso >. https://doi.org/10.5935/0103-4014.20180006.

GONZÁLEZ REY, Fernando. Pesquisa qualitativa e subjetividade: Os processos de construção da informação. São Paulo: Pioneira Thomson Learning, 2005.

GUARESCHI, Neuza Maria Fátima et al. O Cotidiano de Meninos e Meninas na Favela:problematizando as Políticas de Identidade. In: Neuza Maria de Fátima Guareschi; Michel Euclides Bruschi (Orgs.). Psicologia Social nos Estudos Culturais. Petrópolis, p. 129-158, 2003.

GERSCHMAN, Silvia. Miragem da Pós-modernidade. Democracia e Políticas Sociais no Contexto da Globalização. Fiocruz, Rio de Janeiro, 1997.

HALL, Stuart. A identidade cultural na pós-modernidade. Rio de Janeiro: DP\&A, 1997.

Da Diáspora: identidades e mediações culturais. Tradução de Adelaine La Guardia Resende et al. Belo Horizonte: EdUFMG, 2003.

HUNTINGTON, Samuel P. A ordem política nas sociedades em mudança. Tradução de Pinheiro Lemos. Rio de Janeiro: Forense-Universitária; São Paulo: Edusp,1975.

JODELET, Denise. O movimento de retorno ao sujeito e a abordagem das representações sociais. Sociedade e Estado, v. 24, n. 3, p. 679-712, 2009.

LASH, Scott. Sociology of Postmodernism. Londres: Routledge, 1990. 
LIPSET, Seymour M. O homem político. Tradução de Cláudio Gonçalves Couto. Rio de Janeiro: Zahar, 1967.

MARX, Karl. O Manifesto Comunista. Álvaro Pina e Ivana Jinkings. São Paulo: Boitempo, 1998.

MIGUEL, Luis Felipe. "Teoria democrática atual: esboço de mapeamento". BIB - Revista Brasileira de Informação Bibliográfica em Ciências Sociais, São Paulo, n. 59, p. 5-42, 2005.

MINAYO, Maria Cecília de Souza. Ciência, técnica e arte: o desafio da pesquisa social. Em: MINAYO, Maria Cecília de Souza (org). Pesquisa social: teoria, método e criatividade, Petrópolis: Vozes, 2000.

O desafio do conhecimento: pesquisa qualitativa em saúde. São Paulo: HUCITEC; Rio de Janeiro: ABRASCO, 1992.

PUTNAM, Robert D. Comunidade e democracia: a experiência da Itália moderna. Tradução de Luiz Alberto Monjardim. 5a. Ed. Rio de Janeiro: Editora FGV, 2006.

ROLNIK, Suely. Novas figuras do caos. Mutações da subjetividade contemporânea. In: Lúcia Santaella; Jorge Albuquerque Vieira (Orgs.). Caos e Ordem na Filosofia e nas Ciências. São Paulo: Face e Fapesp, p. 206-21, 1999.

ROUSSEAU, Jean-Jacques. Do Contrato Social. Tradução de PietroNassetti. São Paulo: Editora Martin Claret, 2004.

SCHUMPETER, Joseph A. Capitalismo, Socialismo e Democracia. Tradução de Ruy Jungmann. Rio de Janeiro: Editora Fundo de Cultura, 1961.

SORJ, Bila. Anti-semitismo na Europa hoje. Novos estudos - CEBRAP, n. 79, p. 97-115, 2007. Disponivel em <http://www.scielo.br/scielo.php?script=sci_arttext\&pid=S0101$33002007000300005 \& \operatorname{lng}=$ en\&nrm=iso $>$.

doi: http://dx.doi.org/10.1590/S0101-33002007000300005.

TOCQUEVILLE, A. A democracia na América. Tradução de Neil Ribeiro da Silva. Belo Horizonte: Itatiaia; São Paulo: Universidade de São Paulo, 1987.

WEBER, Max. Ciência e Política: duas vocações. Tradução de Leonildas Hegenberg e Octany Silveira da Mota. São Paulo: Editora Cultrix, 2000.

Parlamento e Governo na Alemanha Reordenada: crítica política do funcionalismo e da natureza dos partidos. Tradução de Karin Bakker de Araújo. Petrópolis: Editora Vozes, 1993.

YOUNG, Iris Marion. Representação política, identidade e minorias. Lua Nova, n. 67, p. 139190, 2006. Disponível em <http://www.scielo.br/scielo.php?script=sci_arttext\&pid=S0102$64452006000200006 \&$ Ing $=$ pt\&nrm=iso>

doi: https://doi.org/10.1590/S0102-64452006000200006. 